OPEN ACCESS

Edited by: Renato Cutrera,

Bambino Gesù Ospedale Pediatrico (IRCCS), Italy

Reviewed by:

Yusei Ohshima,

University of Fukui, Japan Elisabetta Calamelli,

Università degli Studi di Bologna, Italy

${ }^{*}$ Correspondence:

Maria A. Tosca

mariangelatosca@gaslini.org

Specialty section: This article was submitted to Pediatric Pulmonology, a section of the journal Frontiers in Pediatrics

Received: 24 May 2018

Accepted: 30 July 2018 Published: 21 August 2018

Citation:

Tosca MA, Licari A, Olcese $R$, Marseglia G, Sacco $O$ and Ciprandi $G$ (2018) Immunotherapy and Asthma in Children. Front. Pediatr. 6:231. doi: 10.3389/fped.2018.00231

\section{Immunotherapy and Asthma in Children}

\author{
Maria A. Tosca ${ }^{1 *}$, Amelia Licari ${ }^{2}$, Roberta Olcese ${ }^{1}$, Gianluigi Marseglia ${ }^{2}$, Oliviero Sacco ${ }^{3}$ \\ and Giorgio Ciprandi ${ }^{4}$
}

${ }^{1}$ Department of Pediatrics, Allergy Center, Istituto Giannina Gaslini (IRCCS), Genoa, Italy, ${ }^{2}$ Department of Pediatrics, Ospedale San Matteo (IRCCS), Pediatrics Clinic, University of Pavia, Pavia, Italy, ${ }^{3}$ Pediatric Pulmonology and Endoscopy, Istituto Giannina Gaslini (IRCCS), Genoa, Italy, ${ }^{4}$ Allergy Clinic, Ospedale San Martino (IRCCS), Genoa, Italy

Allergen immunotherapy (AIT) is still the only disease-modifying treatment strategy for IgE-mediated allergic diseases, with consolidated evidence both in adults and children. AIT is effective in determining clinical improvement of allergic rhinitis and asthma, such as reduced symptoms, medication use, and improvement of quality of life, with a long-lasting effect after cessation of treatment. Results from recent clinical studies have implemented the evidence of effectiveness and safety of allergen immunotherapy for the treatment of allergic asthma, so that the current asthma guidelines now recommend sublingual immunotherapy as an add-on therapy for asthma in adults and adolescents with house dust mite allergy, allergic rhinitis, and exacerbations despite low-to-moderate dose ICS, with forced expiratory volume in 1 second more than $70 \%$ predicted. AIT may also reduce the risk of progression from allergic rhinitis to asthma in children and prevent the onset of new sensitizations, thus representing a potentially preventive method of treatment. The aim of this review is to present an updated overview of the clinical indications of AIT, with particular reference to pediatric asthma, of the mechanisms of clinical and immunological tolerance to allergens, and of the potential biomarkers predicting clinical response.

Keywords: allergen immunotherapy, subcutaneous immunotherapy, sublingual immunotherapy, allergic rhinitis, asthma

\section{INTRODUCTION}

Allergen immunotherapy (AIT) is the administration of the causal allergen to control allergic inflammation and symptoms. AIT has been used for over a century and it is actually considered the only disease-modifying treatment strategy for IgE-mediated allergic diseases, as causing a persistent immunological and clinical tolerance toward the causal allergen (1).

Both subcutaneous AIT (SCIT) and sublingual (SLIT) are used and accepted as effective treatments for adults and children with allergic rhinitis (AR) with or without asthma $(2,3)$. Historically, SCIT was early proposed as the first route of AIT administration, since first report (4). However, despite its proven effectiveness, the use of SCIT is still limited by the need for frequent injections by a doctor over a minimum of 3 years, and, mostly important, the potential occurrence of systemic severe reactions. Consequently, SCIT should be administered in a medical setting by clinicians able to manage anaphylaxis (1). Furthermore, the risk of systemic reactions to SCIT is greater in subjects with uncontrolled asthma and with accelerated dosing schedules (5). Given these disadvantages, SLIT may represent a viable alternative to SCIT, mainly in children, allowing safe self-administration at home (6-8). So, route selection vaccine is based on availability or approval, cost, and the patient's age or the physician's or patient's preference (9). 
SCIT or SLIT products cannot be actually compared due to their heterogeneous composition and allergen concentration (10). Existing studies suggest that both may induce similar immunologic changes (11). Allergens are used for SCIT as aqueous or physically-adsorbed (depot) extracts, as well as chemically modified allergens (allergoids) as depot formulations. Allergens for SLIT are used as drops or tablets. Waiting for a harmonized and international AIT products regulation, they are still available most commonly either by being distributed as "named patient products" (NPP), prepared simply in compliance with Good Manufacturing Practice, and by obtaining a formal marketing authorization (12). SLIT tablets for grass pollen and house dust mite (HDM) have been recently registered for use in children, adolescents, and adults $(13,14)$.

Through complex molecular and cellular mechanisms inducing immune tolerance, effective AIT may modify the natural course of allergic disease, both preventing the onset of new sensitizations and the clinical disease progression (from rhinitis to asthma). AIT may also control allergic symptoms that are unresponsive to avoidance strategies and medications, reduce medication use, and improve quality of life, with a long-lasting effect after cessation $(15,16)$. Results from recent trials have implemented the evidence of effectiveness and safety of AIT for the treatment of allergic asthma, so that updated asthma guidelines now recommend SLIT as an add-on therapy for asthma in adults and adolescents with HDM allergy, under certain conditions (3).

The aim of this review is to present an updated overview of the clinical indications of AIT, with particular reference to pediatric asthma, of the mechanisms of clinical and immunological tolerance to allergens, and of the potential biomarkers predicting clinical response. A literature search was performed through Medline via Pubmed to identify all relevant articles published in English, on the basis of the following three search terms: "allergen immunotherapy", "children," and "asthma." From the articles retrieved in the first round of search, additional references were identified by a manual search among the cited references.

\section{OVERVIEW OF THE MECHANISMS OF ALLERGEN IMMUNOTHERAPY}

AIT targets the upper and lower respiratory allergic symptoms by modulating the IgE-mediated response consequent to allergen exposure. Through multiple mechanisms involving both innate and adaptive immunity, AIT regulates T- and B-cells, changing antibody isotypes, decreases mediator release, and migration of inflammatory cells to tissues (17-19).

A key mechanism in inducing immunologic tolerance is the upregulation of allergen-specific T-regulatory (Treg) cells and B-regulatory (Breg) cells, which primarily down-regulate the $\mathrm{Th}_{2}$ response (19) (Table 1). Regulatory cells inhibit the activation of allergen-specific $\mathrm{Th}_{2}$ lymphocytes, suppress allergic inflammation, and ultimately shift toward a Type 1-mediated immune response, releasing cytokines, interleukin (IL)-10 and transforming growth factor- $\beta$ (TGF- $\beta$ ) (20).
TABLE 1 | Mechanisms of immunologic tolerance mediated by $T$ and $B$ regulatory cells during allergen immunotherapy.

\section{Treg-mediated mechanisms}

Release regulatory cytokines (IL-10, TGF- $\beta$, and IL-35)

Induce tolerogenic DCs subsets

Reduced number of ILC2

Suppress activation of allergen-specific $\mathrm{Th}_{2}$ lymphocytes

Downregulate the expression of $\mathrm{FC} \varepsilon \mathrm{RI}$ receptors on mast cells,

Decrease allergen-specific lgE synthesis

Promote B-cell production of $\lg _{4}$ antibody

\section{Breg-mediated mechanisms}

Release regulatory cytokines (IL-10, TGF- $\beta$ )

Induce the synthesis of IgG4 blocking antibodies

Inhibit activation and proliferation of effector $T$ Iymphocytes

Suppress $\mathrm{Th}_{2}$-dependent inflammation

Promote T-cell expression of Foxp3 and generation of functional Treg cells

Breg, B regulatory; DCs, dendritic cells; FCERl, high-affinity receptor for the FC region of IgE; Foxp3, forkhead box P3; IgE, immunoglobulin E; IgG IL, interleukin; ILC2, innate lymphoid cells type 2; TGF, transforming growth factor; $T h_{2}, T$ helper type 2; Treg, T regulatory.

After high-dose allergen administration by AIT, dendritic cells (DCs) produce IL-12, IL-27, and IL-10, generating and activating distinct phenotypes of Tregs: natural (nTreg) and inducible (iTreg) cells (17, 19). Both nTreg and iTreg cells suppress allergic response through direct and indirect mechanisms: release regulatory cytokines (IL-10, TGF- $\beta$, and IL-35), directly induce tolerogenic DCs subsets, suppress activation of allergenspecific $\mathrm{Th}_{2}$ lymphocytes, downregulate the expression of FCeRI receptors on mast cells, decrease allergen-specific IgE synthesis, and promote B-cell production of IgG4 in an allergen-independent manner (17, 19). IL-10 directly inhibits T-cell-associated cytokines, including IL-4 and IL-5, reduces proinflammatory cytokine from mast cells and eosinophils, decreases allergen-specific IgE production, and increases $\operatorname{IgA}$ and $\mathrm{IgG}_{4}$ levels (19). Competitively binding to the same site epitopes recognized by $\mathrm{IgE}, \mathrm{IgG}_{4}$ exert a sort of "immunologic blockade" inhibiting mast cell and basophil degranulation. In addition, $\mathrm{IgG}_{4}$ has been proposed to co-stimulate the inhibitory

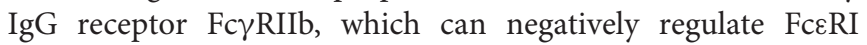
signaling and in turn inhibit effector cell activation. $\operatorname{IgG}_{4}$ also inhibit IgE-mediated facilitation of allergen presentation to T lymphocytes (20). TGF- $\beta$ suppresses both activity and proliferation of $\mathrm{Th}_{2}$ cells and innate lymphoid cells type 2 (ILC2), thus inhibiting $\mathrm{Th}_{2}$-cytokines (IL-4, IL-5, IL-9, and IL13), and consequently decreasing the activation of eosinophils, basophils, mast cells and IgE-secreting B lymphocytes $(17,19)$.

Bregs play a key role in inducing immune tolerance to allergens, directly promoting the synthesis of allergen-specific $\mathrm{IgG}_{4}$, inhibiting activation and proliferation of effector $\mathrm{T}$ lymphocytes, suppressing $\mathrm{Th}_{2}$-dependent inflammation, increasing Treg cells (21). Overall, AIT is able to restore the impaired allergen tolerance. 


\section{CLINICAL INDICATIONS OF AIT IN CHILDREN WITH RESPIRATORY ALLERGY}

AIT should be considered in patients who have AR with or without conjunctivitis, and/or asthma with documented sensitization consisting with symptoms after sensitizing-allergen exposure (22). Candidates for AIT are patients with uncontrolled symptoms by medications and/or environmental prevention or experiencing drug adverse effects or wishing reduction of longterm treatment (22).

The evidence of efficacy and safety of AIT in AR and/or asthma have been documented both in adults and children (6, $23,24)$.

\section{Allergic Rhinitis}

AIT is the established treatment of choice for AR patients experiencing failed allergen avoidance and/or medical therapy $(2,25)$. European Academy of Allergy and Clinical Immunology (EAACI) 2018 guidelines recommend AIT in AR patients, with or without conjunctivitis, with evident sensitization to one or more clinically relevant allergens and moderate-to-severe symptoms despite regular and/or avoidance strategies $(6,26)$. This statement is based on a body of international trials evidence providing a comprehensive assessment of AIT in AR: both SCIT and SLIT are effective for seasonal and perennial AR in achieving shortterm improvements in symptom, medication use, and combined symptom and medication scores $(27,28)$. The evidence of longerterm effectiveness is documented for grass AIT, especially for tablets (26). Thus, standardized and validated AIT products should be used when available, and a product-specific evaluation of evidence is actually recommended before initiating treatment with a specific product $(6,26)$.

With particular reference to children, AIT should be considered similarly to adults (26). Although major gaps still exist for the pediatric age (29), it can be actually recommended: (i) continuous, pre- and pre/co-seasonal SCIT for children with seasonal AR; (ii) continuous SCIT for perennial AR (weak recommendation due to the lack of exclusive pediatric data); (iii) pre-co-seasonal and continuous SLIT for seasonal AR (both tablet and drop); (iv) poor evidence for perennial AR, although the effectiveness of SLIT tablet approach has been demonstrated in the short term in mixed adult/adolescent studies (26). It is also recommended a minimum of 3-year course to achieve long-term efficacy (6).

\section{Asthma}

Asthma is a common chronic disease affecting all age groups, with up to $20 \%$ of children aged 6-7 years experiencing severe wheezing episodes within a year (30). The actual asthma management is control-based: therapeutic strategies are based on a stepwise approach and adjusted in a continuous cycle involving assessment, treatment and review $(3,31-33)$. However, standard pharmacotherapy does not affect the underlying pathogenetic immune response, as it is withdrawn symptoms and inflammation occur again.

SLIT is actually recommended as add-on treatment option in adult HDM-sensitized asthmatics with concomitant AR who have exacerbations despite inhaled corticosteroids (ICS] treatment, with forced expiratory volume in $1 \mathrm{~s}\left(\mathrm{FEV}_{1}\right)$ more than $70 \%$ predicted, as stated in the latest Global Initiative for Asthma Report (GINA) update (3). Asthma must be mild-to-moderate and allergic, and well or "partially" controlled by standard pharmacotherapy; asthma control has to be maintained throughout AIT course (34). Conversely, AIT is still restricted in patients with uncontrolled asthma, as it represents a significant risk factor for serious and even fatal adverse reactions (5). Coupling anti-IgE biological therapy (omalizumab) with AIT has been proposed as a suitable option to increase SCIT effectiveness and safety (35-38).

This significant change in the GINA strategy draws upon recent Phase III clinical trial evaluating the treatment of asthma with the standardized quality (SQ) HDM SLIT-tablet in adults: the addition of HDM SLIT to maintenance therapies reduced ICS or the time to first exacerbation upon ICS reduction, suggesting that SQ HDM SLIT-tablet may improve overall asthma control (39). While these data require further studies to confirm longterm efficacy and safety of this product in adults, less information is available for adolescents $(40,41)$ and studies are in progress in children (42). HDM sensitization in early childhood represents an important risk factor for the development of asthma (43) and is linked to the impairment of lung function in schoolage asthmatic children $(43,44)$ and asthma persistence into adulthood (45). So, other single HDM SLIT preparations have been tested in children and adolescents with allergic asthma. Among others, SLIT with the 300 index of reactivity (IR)standardized HDM extract, in children aged 6-18 years with AR with or without allergic asthma, improved rhinitis and/or asthma symptoms scores, together with a reduction of rescue medications (46).

Meta-analyses confirmed the effectiveness and the safety profile of AIT in allergic asthma for adults and children (27, 4751), mainly concerning SLIT in children (22, 52-54). Consistent reduction in combined AR and asthma symptom and medication scores have been demonstrated in pediatric patients with asthma and comorbid AR treated with SLIT $(48,53,55)$. These clinical effects have been also demonstrated to be persistent after AIT discontinuation up to 5 years (56). SCIT has demonstrated effectiveness in controlling asthma and reducing medication use $(49,50,57)$. Meta-analyses of randomized clinical trials using SCIT in asthma have demonstrated a significant reduction in symptoms, medication use, and AHR both in children and adults, while the effect on lung function showed conflicting results (49, 50). Studies conducted in children showed similar results (5861). SCIT may have a long-term impact on childhood asthma, as demonstrated in a prospective study using HDM SCIT: after 3 years of SCIT discontinuation, a global remission of asthma (in particular reduced doses of ICS, lower asthma symptom scores, higher quality of life scores, less AHR, and higher $\mathrm{FEV}_{1}$ ) was reported in treated patients compared to controls (62). In another retrospective study, asthmatics allergic to either HDM or grass pollen, treated with SCIT in childhood, were re-evaluated 9 years after the discontinuation, showing a threetime lower risk of frequent asthma symptoms than controls, 
but without any difference in lung function or medication use (63).

Overall, both SCIT and SLIT appear to be effective for the treatment of AR and asthma in children $(64,65)$. Of particular interest for the pediatric population, it is the AIT ability (both SCIT and SLIT) to reduce ICS doses together with the impact on asthma control. These promising results highlight the immunomodulating pivotal role of AIT in controlling and inducing remission of disease activity. Furthermore, the persistence of these clinical effects after discontinuation separates AIT uniquely from other anti-allergic therapies.

\section{Prevention of Allergy Progression and Asthma Onset}

Over the last decade, the disease-modifying properties of AIT have been largely investigated, mainly focusing on the prevention of allergic sensitization and asthma onset.

Developing new sensitizations is characteristic of the natural history of allergy. A preventive effect of AIT on the onset of new sensitizations has been reported $(1,66)$ and demonstrated in asthmatic children mono-sensitized to $\operatorname{HDM}(67,68)$. However, a recent systematic review and meta-analysis on this topic reported a low level of evidence related to the heterogeneity and the high risk of bias of the included studies $(69,70)$. A recent EAACIfunded meta-analysis highlighted a reduced risk of developing new sensitizations at least over the short period, but none on the long-term (71).

Children with AR have an increased risk of developing asthma later on in life when compared to those without AR, especially those with AHR (72). Few but significant studies investigated disease modification in children, mainly concerning AIT (73-77). The prevention of allergy (PAT) study was a large prospective randomized controlled study to evaluate the preventive effect of SCIT in children (aged 6-14 years) with grass and/or birch AR without asthma (73-75). Actively-treated children had a significantly reduced risk of developing asthma and fewer asthma symptoms after 3-year treatment compared to controls (73). This preventive effect persisted at 5 years (74) and 7 years (75) after SCIT discontinuation. The preventive effect of SLIT was evaluated in two open trials conducted on children with AR with or without asthma: a 3-year course of SLIT improved AR symptoms, reduced onset of asthma, and decreased $\operatorname{AHR}(78,79)$. Although promising, these findings had a major limitation as derived from open studies with a limited number of subjects. The results of the grass tablet asthma prevention (GAP) study, the first randomized, double-blind, placebo-controlled trial, have been recently published (77). The GAP study involved 812 children (aged 5-12 years), with grass-pollen AR and without asthma, who received 3-year SQ grass-SLIT-tablet or placebo and were followed for 2 years after discontinuation (77). Treated children significantly reduced the risk of experiencing asthma symptoms or using asthma medication, as well as AR-related symptoms and medications, at the end of the trial, during the 2-year posttreatment follow-up, and during the entire 5-year trial period (77). Taken together, these studies suggest that AIT might reduce the risk of developing asthma symptoms in children, especially in those with AR. EAACI guidelines on the PAT recommend a 3year course of AIT in children with moderate-to-severe AR and grass/birch pollen allergy, uncontrolled with pharmacotherapy for short-term and possibly long-term prevention of asthma symptoms in addition to improving the control of AR (6, 16).

Finally, the role of AIT in the primary PAT is currently under investigation. In a recent proof of concept study, 111 young children (aged 5-9 months), not sensitized, but at high risk of atopy, were treated with prophylactic HDM SLIT (80). A significant sensitization prevention was demonstrated in the active group; however, no significant preventive effect was observed on HDM sensitization or allergy-related symptoms (80). Further studies are expected to clarify the role of AIT as early-intervention in high-risk children.

\section{PATIENT SELECTION AND BIOMARKERS OF RESPONSE}

Since AIT is allergen-specific, a detailed clinical history and appropriate allergy diagnostic tests are essential to properly identify the triggering clinical relevant allergen(s) (2). In case of polysensitized patients, the identification of major allergens should be supported by the use of componentresolved diagnostics (81). Uncontrolled AR symptoms despite antihistamines and/or topical corticosteroids and allergen avoidance measures and/or side-effects of medication, the duration of AR symptoms, as well as the assessment of asthma control, are essential to consider AIT as a therapeutic option (2). Each patient should be evaluated individually by considering the benefits and the risks, and the ability to comply/cooperate with AIT (26). Although some clinical studies have demonstrated efficacy and safety of AIT in preschool children $(82,83)$, there is no consensus on a specific lower age limit for initiating AIT for respiratory allergy (8). However, this issue still deserves further extensive studies in the perspective of preventive strategies.

Although highly effective, some patients could not respond to AIT treatment. Thus, the identification and validation of potential predictive biomarkers of AIT effectiveness is an active filed of research and could enhance the selection and the clinical management of patients receiving AIT. Biomarkers are quantitative measurement predicting clinical and immunological effects of AIT (84). In particular, ideal biomarkers for AIT should assist in patient selection and identification of responders and predict clinical and immunological response during treatment and after discontinuation of treatment (84). The EAACI Taskforce recently reviewed all candidate biomarkers used in clinical trials of AR patients with or without asthma $(18,84)$ (Table 2). Markers can be cellular (Tregs), humoral (allergenspecific $\left.\operatorname{IgG}_{4}\left(\mathrm{sIgG}_{4}\right), \mathrm{IgE} / \mathrm{IgG}_{4}\right)$, molecular (interleukins), or functional (IgE FAB and blocking factor). Although several studies have included biomarkers as secondary outcomes, specifically AIT biomarker studies are still lacking. To date, raised serum allergen-specific $\operatorname{IgE}(\mathrm{sIgE})$ are considered the only useful biomarker to select candidates for AIT, in the 
TABLE 2 | Potential biomarkers for allergen immunotherapy (AIT).

\begin{tabular}{|c|c|c|c|c|c|}
\hline Categories & $\begin{array}{l}\text { Candidate } \\
\text { biomarkers }\end{array}$ & Domain & Advantages & Disadvantages, unmet need & Possible applications \\
\hline $\begin{array}{l}\text { Biomarkers for } \\
\text { diagnosis }\end{array}$ & $\begin{array}{l}\lg E(s \lg E, \operatorname{tlg} E \\
\text { slgE/tlgE) }\end{array}$ & Antibodies & $\begin{array}{l}\text { Elevated serum lgE levels in } \\
\text { the context of a clear history } \\
\text { of allergic symptoms is a } \\
\text { biomarker for selection of } \\
\text { patients for AIT }\end{array}$ & $\begin{array}{l}\text { No clear correlation with clinical } \\
\text { outcome } \\
\text { Lack of validation in RDBPCT } \\
\text { Lack of standardization of assay } \\
\text { platform and reference ranges/cut-off } \\
\text { values }\end{array}$ & $\begin{array}{l}\text { Prediction of disease } \\
\text { severity and/or progression }\end{array}$ \\
\hline
\end{tabular}

\begin{tabular}{|c|c|c|c|c|c|}
\hline & $\begin{array}{l}\text { CD63, CD203C, } \\
\text { DAO, basophil } \\
\text { histamine release }\end{array}$ & & & & \\
\hline $\begin{array}{l}\text { Biomarkers } \\
\text { predictive of AIT } \\
\text { safety }\end{array}$ & $\begin{array}{l}\text { CD63, CD203c, } \\
\text { DAO, basophil } \\
\text { histamine release }\end{array}$ & Basophil activation & $\begin{array}{l}\text { Small amount of blood } \\
(<2 \mathrm{ml}) \text { is required to } \\
\text { perform the test }\end{array}$ & $\begin{array}{l}\text { Mechanism of allergen induced } \\
\text { basophil hyperresponsiveness during } \\
\text { AIT not completely known } \\
\text { Limited number of studies } \\
\text { Need for standardized assays }\end{array}$ & $\begin{array}{l}\text { Reduced risk of side effects } \\
\text { and improvement of } \\
\text { patients' compliance to } \\
\text { treatment }\end{array}$ \\
\hline & slgE/total lgE & Antibodies & $\begin{array}{l}\text { Potential positive predictive } \\
\text { biomarker of response for } \\
\text { AIT }\end{array}$ & Lack of validation in RDBPC & $\begin{array}{l}\text { Prediction of clinical } \\
\text { response }\end{array}$ \\
\hline & $\lg E \mathrm{FAB}, \lg \mathrm{E}-\mathrm{BF}$ & $\begin{array}{l}\text { Serum Inhibitory } \\
\text { activity for lgE }\end{array}$ & $\begin{array}{l}\text { Highly reproducible } \\
\text { serum-based assay } \\
\text { Association with clinical } \\
\text { outcome has been reported } \\
\text { in some studies }\end{array}$ & $\begin{array}{l}\text { Availability limited to specialized } \\
\text { centers or laboratories }\end{array}$ & \\
\hline \multirow[t]{3}{*}{$\begin{array}{l}\text { Not yet } \\
\text { determined }\end{array}$} & $\begin{array}{l}\text { CCR3, ECP, eotaxin, } \\
\text { IFN- } \gamma, \text { IL-2, IL-2R, } \\
\text { IL-4/5/6, IL-8/9/10, } \\
\text { IL-13/18, MCP-1, } \\
\text { TARC, transthyretin }\end{array}$ & $\begin{array}{l}\text { Cytokines and } \\
\text { chemokines }\end{array}$ & $\begin{array}{l}\text { May be useful to further } \\
\text { explore mechanisms of AIT }\end{array}$ & No correlation with clinical outcome & Not known \\
\hline & DCs, Breg, Treg & $\begin{array}{l}\text { Cellular } \\
\text { biomarkers }\end{array}$ & $\begin{array}{l}\text { Early biomarkers of } \\
\text { immunologic response }\end{array}$ & $\begin{array}{l}\text { Not routinely performed, limited } \\
\text { applications in clinical practice } \\
\text { No clear correlation with clinical } \\
\text { outcome }\end{array}$ & $\begin{array}{l}\text { Prediction of immunological } \\
\text { response }\end{array}$ \\
\hline & $\begin{array}{l}\text { SPT, Id, In, chamber } \\
\text { studies }\end{array}$ & In vivo biomarkers & $\begin{array}{l}\text { Provocation tests used as } \\
\text { surrogate biomarkers of } \\
\text { clinical response to AIT } \\
\text { Provocation methods are } \\
\text { recommended as primary } \\
\text { endpoints in } \\
\text { proof-of-concept and } \\
\text { dose-finding trials of AIT }\end{array}$ & $\begin{array}{l}\text { Standardization and validation differ } \\
\text { from the various challenge protocols } \\
\text { Comparison between provocation } \\
\text { test results and symptoms after } \\
\text { natural exposure are currently lacking }\end{array}$ & $\begin{array}{l}\text { Prediction of clinical } \\
\text { response }\end{array}$ \\
\hline
\end{tabular}

Adapted from Shamii et al. (84). BF, binding factor; Breg, B regulatory cell; CCR, chemokine receptor; CD, cluster of differentiation; DAO, diamine oxidase; DC, dendritic cell; ECP, eosinophil cationic protein; FAB, facilitated antigen binding; Id, intradermal test; IFN, interferon; Ig, immunoglobulin; IL, interleukin; In, intranasal test; MCP, monocyte chemoattractive protein; RDBPCT, Randomized double-blinded placebo-controlled trial; slg, allergen-specific Ig; SPT, skin prick test; TARC, thymus and activation-regulated chemokine; tlg, total Ig; Treg, T regulatory cell.

context of a clear history of symptoms on exposure to the relevant allergen (84). In particular, preliminary data suggest that higher levels of sIgE in children could be helpful to predict AIT efficacy (85). Furthermore, sIgG4, sIgE/total $\mathrm{IgE}$ ratio, and $\mathrm{IgE}-\mathrm{FAB}$ are in the pipeline as candidate biomarkers for compliance and response to AIT, respectively (84). More research is needed to confirm and interpret the possible association of biomarkers with both clinical response and persistence of clinical benefit after discontinuation of AIT.

\section{CONCLUSIONS}

AIT represents a valuable therapeutic option, especially in childhood, to modify the progression of allergic disease. AIT may be particularly useful in children with AR and new-onset asthma because it may modify the long-term prognosis of their airway disease. Both SCIT and SLIT seem to be effective in pediatric allergic asthma, showing a promising steroid-sparing effect of which patients treated with high-dose pharmacotherapy for a long term could benefit most. To date, uncontrolled asthma 
remains a clear contraindication for AIT treatment; however, coupling novel biological therapies with AIT could represent a novel approach to treat these patients with high risk of adverse reactions. Over the last decade considerable advances in the AIT approach have been also made to move forward this therapeutic field in the context of personalized medicine. The advanced knowledge of the mechanisms of sustaining clinical and immunological tolerance toward allergens, the implementation of vaccination strategies (using recombinant allergen extracts, or modified extracts at increased safety/efficacy, or adjuvants to further stimulate the immune system), the implementation and diffusion of international guidelines, the definition of regulatory aspects such as standardization and registration of AIT products, the standardization of clinical trial outcomes, as

\section{REFERENCES}

1. Jutel M, Agache I, Bonini S, Burks AW, Calderon M, Canonica W, et al. International consensus on allergy immunotherapy. J Allergy Clin Immunol. (2015) 136:556-68. doi: 10.1016/j.jaci.2015.04.047

2. Brozek JL, Bousquet J, Agache I, Agarwal A, Bachert C, BosnicAnticevich S, et al. Allergic rhinitis and its impact on asthma (ARIA) guidelines-2016 revision. J Allergy Clin Immunol. (2017) 140:950-58. doi: $10.1016 /$ j.jaci.2017.03.050

3. Global Initiative for Asthma. GINA Guidelines 2018. Global Strategy for Asthma Management and Prevention (2018). Available online at: http://www. ginasthma.org/

4. Noon L. Prophylactic inoculation against hayfever. Lancet (1911) 1:1572 doi: 10.1016/S0140-6736(00)78276-6

5. Pitsios C, Demoly P, Bilò MB, Gerth van Wijk R, Pfaar O, Sturm GJ, et al. Clinical contraindications to allergen immunotherapy: an EAACI position paper. Allergy (2015) 70:897-909. doi: 10.1111/all.12638

6. Muraro A, Roberts G, Halken S, Agache I, Angier E, Fernandez-Rivas M, et al. EAACI guidelines on allergen immunotherapy: executive statement. Allergy (2018) 73:739-43. doi: 10.1111/all.13420

7. Rodríguez Del Río P, Vidal C, Just J, Tabar AI, Sanchez-Machin I, Eberle $\mathrm{P}$, et al. The European survey on adverse systemic reactions in allergen immunotherapy (EASSI): a paediatric assessment. Pediatr Allergy Immunol. (2017) 28:60-70. doi: 10.1111/pai.12660

8. Pajno GB, Bernardini R, Peroni D, Arasi S, Martelli A, Landi M, et al. Clinical practice recommendations for allergen-specific immunotherapy in children: the Italian consensus report. Ital J Pediatr. (2017) 43:13. doi: 10.1186/s13052-016-0315-y

9. Burks AW, Calderon MA, Casale T, Cox L, Demoly P, Jutel M, et al. Update on allergy immunotherapy: american academy of allergy, asthma \& immunology/european academy of allergy and clinical immunology/PRACTALL consensus report. J Allergy Clin Immunol. (2013) 131:1288.e3-96. doi: 10.1016/j.jaci.2013.01.049

10. Bauer CS, Rank MA. Comparative efficacy and safety of subcutaneous versus sublingual immunotherapy. J Allergy Clin Immunol. (2014) 134:765.e2-765. doi: 10.1016/j.jaci.2014.07.024

11. Nelson HS, Makatsori M, Calderon MA. Subcutaneous immunotherapy and sublingual immunotherapy: comparative efficacy, current and potential indications, and warnings - United States Versus Europe. Immunol Allergy Clin North Am. (2016) 36:13-24. doi: 10.1016/j.iac.2015.0 8.005

12. Bonertz A, Roberts GC, Hoefnagel M, Timon M, Slater JE, Rabin RL, et al. Challenges in the implementation of EAACI guidelines on allergen immunotherapy: a global perspective on the regulation of allergen products. Allergy (2018) 73:64-76. doi: 10.1111/all.13266

13. EMA. Committee for medicinal products for human use (CHMP). Guideline on the Clinical Development of Products for Specific Immunotherapy for the Treatment of Allergic Diseases. London (2011). well as the planning of future dedicated pediatric studies, will all implement the evidence of efficacy and safety of AIT for allergic children.

\section{AUTHOR CONTRIBUTIONS}

All authors made substantial contribution to the conception of the work, reviewed the literature on the subject, and drafted the final version of the manuscript. AL and MT revised it critically for important intellectual content. All authors finally approved the version to be published and agreed to be accountable for all aspects of the work in ensuring that questions related to the accuracy or integrity of any part of the work are appropriately investigated and resolved.
14. EMA. Committee for Medicinal Products for human use (CHMP). Guideline on Allergen Products Standardization and Quality Issues. London (2014).

15. Jutel M, Agache I, Bonini S, Burks AW, Calderon M, Canonica W, et al. International consensus on allergen immunotherapy II: mechanisms, standardization, and pharmacoeconomics. J Allergy Clin Immunol. (2016) 137:358-68. doi: 10.1016/j.jaci.2015.12.1300

16. Halken S, Larenas-Linnemann D, Roberts G, Calderón MA, Angier E, Pfaar O, et al. EAACI guidelines on allergen immunotherapy: prevention of allergy. Pediatr Allergy Immunol. (2017) 28:728-45. doi: 10.1111/pai. 12807

17. Shamji MH, Durham SR. Mechanisms of allergen immunotherapy for inhaled allergens and predictive biomarkers. J Allergy Clin Immunol. (2017) 140:148598. doi: 10.1016/j.jaci.2017.10.010

18. Berings M, Karaaslan C, Altunbulakli C, Gevaert P, Akdis M, Bachert C, et al. Advances and highlights in allergen immunotherapy: on the way to sustained clinical and immunologic tolerance. J Allergy Clin Immunol. (2017) 140:1250-67. doi: 10.1016/j.jaci.2017.08.025

19. Akdis CA, Akdis M. Mechanisms of allergen-specific immunotherapy and immune tolerance to allergens. World Allergy Organ J. (2015) 8:17. doi: 10.1186/s40413-015-0063-2

20. Kappen JH, Durham SR, Veen HI, Shamji MH. Applications and mechanisms of immunotherapy in allergic rhinitis and asthma. Ther Adv Respir Dis. (2017) 11:73-86. doi: 10.1177/1753465816669662

21. van de Veen W, Wirz OF, Globinska A, Akdis M. Novel mechanisms in immune tolerance to allergens during natural allergen exposure and allergen-specific immunotherapy. Curr Opin Immunol. (2017) 48:74-81. doi: 10.1016/j.coi.2017.08.012

22. Cox L, Nelson H, Lockey R, Calabria C, Chacko T, Finegold I, et al. Allergen immunotherapy: a practice parameter third update. J Allergy Clin Immunol. (2011) 127:S1-55. doi: 10.1016/j.jaci.2010.09.034

23. Larenas-Linnemann D, Luna-Pech JA. What you should not miss from the systematic reviews and meta-analyses on allergen-specific immunotherapy in 2017. Curr Opin Allergy Clin Immunol. (2018) 18:168-176. doi: 10.1097/ACI.0000000000000439

24. Pfaar O, Alvaro M, Cardona V, Hamelmann E, Mösges R, Kleine-Tebbe J. Clinical trials in allergen immunotherapy: current concepts and future needs. Allergy (2018). doi: 10.1111/all.13429. [Epub ahead of print].

25. Wise SK, Lin SY, Toskala E, Orlandi RR, Akdis CA, Alt JA, et al. International consensus statement on allergy and rhinology: allergic rhinitis. Int Forum Allergy Rhinol. (2018) 8:108-352. doi: 10.1002/alr.22073

26. Roberts G, Pfaar O, Akdis CA, Ansotegui IJ, Durham SR, Gerth van Wijk R, et al. EAACI guidelines on allergen immunotherapy: allergic rhinoconjunctivitis. Allergy (2018) 73:765-98. doi: 10.1111/all.13317

27. Dhami S, Nurmatov U, Arasi S, Khan T, Asaria M, Zaman H, et al. Allergen immunotherapy for allergic rhinoconjunctivitis: a systematic review and meta-analysis. Allergy (2017) 72:1597-1631. doi: 10.1111/all.13201

28. Nurmatov U, Dhami S, Arasi S, Roberts G, Pfaar O, Muraro A, et al. Allergen immunotherapy for allergic rhinoconjunctivitis: a systematic 
overview of systematic reviews. Clin Transl Allergy (2017) 7:24. doi: 10.1186/s13601-017-0159-6

29. Comberiati P, Marseglia GL, Barberi S, Passalacqua G, Peroni DG Allergen-specific immunotherapy for respiratory allergy in children: unmet needs and future goals. J Allergy Clin Immunol Pract. (2017) 5:946-50. doi: 10.1016/j.jaip.2017.01.024

30. Lai CK, Beasley R, Crane J, Foliaki S, Shah J, Weiland S, et al. Global variation in the prevalence and severity of asthma symptoms: phase three of the international study of asthma and allergies in childhood (ISAAC). Thorax (2009) 64:476-83. doi: 10.1136/thx.2008.106609

31. Taylor DR, Bateman ED, Boulet LP, Boushey HA, Busse WW, Casale TB, et al. A new perspective on concepts of asthma severity and control. Eur Respir J. (2008) 32:545-54. doi: 10.1183/09031936.00155307

32. Dinakar C, Chipps BE. Clinical tools to assess asthma control in children. Pediatrics (2017) 139:e20163438. doi: 10.1542/peds.2016-3438

33. Licari A, Marseglia GL. Current and future challenges in pediatric severe asthma. Curr Med Res Opin. (2018) 34:943-4. doi: 10.1080/03007995.2018.1439463

34. Tsabouri S, Mavroudi A, Feketea G, Guibas GV. Subcutaneous and sublingual immunotherapy in allergic asthma in children. Front Pediatr. (2017) 5:82. doi: $10.3389 /$ fped.2017.00082

35. Licari A, Marseglia A, Caimmi S, Castagnoli R, Foiadelli T, Barberi $S$, et al. Omalizumab in children. Paediatr Drugs (2014) 16:491-502. doi: $10.1007 / \mathrm{s} 40272-014-0107-\mathrm{z}$

36. Ciprandi G, Marseglia GL, Castagnoli R, Valsecchi C, Tagliacarne C, Caimmi $\mathrm{S}$, et al. From IgE to clinical trials of allergic rhinitis. Expert Rev Clin Immunol. (2015) 11:1321-33. doi: 10.1586/1744666XX.2015.1086645

37. Licari A, Castagnoli R, Bottino C, Marseglia A, Marseglia G, Ciprandi G. Emerging drugs for the treatment of perennial allergic rhinitis. Expert Opin Emerg Drugs (2016) 21:57-67. doi: 10.1517/14728214.2016.1139082

38. Licari A, Castagnoli R, Brambilla I, Marseglia A, Tosca MA, Marseglia GL, et al. New approaches for identifying and testing potential new anti-asthma agents. Expert Opin Drug Discov. (2018) 13:51-63. doi: 10.1080/17460441.2018.1396315

39. Virchow JC, Backer V, Kuna P, Prieto L, Nolte H, Villesen HH, et al. Efficacy of a house dust mite sublingual allergen immunotherapy tablet in adults with allergic asthma: a randomized clinical trial. JAMA (2016) 315:1715-25. doi: 10.1001/jama.2016.3964

40. Mauro M, Boni E, Makri E, Incorvaia C. Pharmacodynamic and pharmacokinetic evaluation of house dust mite sublingually administered immunotherapy tablet in the treatment of asthma. Expert Opin Drug Metab Toxicol. (2015) 11:1937-43. doi: 10.1517/17425255.2015.1113255

41. Mosbech H, Deckelmann R, de Blay F, Pastorello EA, Trebas-Pietras E, Andres LP, et al. Standardized quality (SQ) house dust mite sublingual immunotherapy tablet (ALK) reduces inhaled corticosteroid use while maintaining asthma control: a randomized, double-blind, placebo-controlled trial. J Allergy Clin Immunol. (2014) 134:568.e7-75. doi: 10.1016/j.jaci.2014.03.019

42. Maloney J, Prenner BM, Bernstein DI, Lu S, Gawchik S, Berman G, et al. Safety of house dust mite sublingual immunotherapy standardized quality tablet in children allergic to house dust mites. Ann Allergy Asthma Immunol. (2016) 116:59-65. doi: 10.1016/j.anai.2015.1 0.024

43. Lodge CJ, Lowe AJ, Gurrin LC, Hill DJ, Hosking CS, Khalafzai RU, et al. House dust mite sensitization in toddlers predicts current wheeze at age 12 years. J Allergy Clin Immunol. (2011) 128:782.e9-88. doi: 10.1016/j.jaci.2011.0 6.038

44. Lau S, Illi S, Sommerfeld C, Niggemann B, Bergmann R, von Mutius E, et al. Early exposure to house-dust mite and cat allergens and development of childhood asthma: a cohort study. Lancet (2000) 356:1392-7. doi: 10.1016/S0140-6736(00)02842-7

45. Illi S, von Mutius E, Lau S, Niggemann B, Grüber C, Wahn U, et al. Perennial allergen sensitisation early in life and chronic asthma in children: a birth cohort study. Lancet (2006) 368:763-70. doi: 10.1016/S0140-6736(06)69286-6

46. Ferrés J, Justicia JL, García MP, Muñoz-Tudurí M, Alvà V. Efficacy of high-dose sublingual immunotherapy in children allergic to house dust mites in real-life clinical practice. Allergol Immunopathol. (2011) 39:122-7. doi: 10.1016/j.aller.2010.01.008
47. Rice JL, Diette GB, Suarez-Cuervo C, Brigham EP, Lin SY, Ramanathan $\mathrm{M} \mathrm{Jr}$, et al. Allergen-specific immunotherapy in the treatment of pediatric asthma: a systematic review. Pediatrics (2018) 141:e20173833. doi: $10.1542 /$ peds.2017-3833

48. Penagos M, Passalacqua G, Compalati E, Baena-Cagnani CE, Orozco S, Pedroza A, et al. Meta-analysis of the efficacy of sublingual immunotherapy in the treatment of allergic asthma in pediatric patients, 3 to 18 years of age. Chest (2008) 133:599-609. doi: 10.1378/chest.06-1425

49. Ross RN, Nelson HS, Finegold I. Effectiveness of specific immunotherapy in the treatment of asthma: a meta-analysis of prospective, randomized, double-blind, placebo-controlled studies. Clin Ther. (2000) 22:329-41. doi: 10.1016/S0149-2918(00)80037-5

50. Abramson MJ, Puy RM, Weiner JM. Injection allergen immunotherapy for asthma. Cochrane Database Syst Rev. (2010) 8:CD001186. doi: 10.1002/14651858.CD001186.pub2

51. van de Griendt EJ, Tuut MK, de Groot H, Brand PLP. Applicability of evidence from previous systematic reviews on immunotherapy in current practice of childhood asthma treatment: a GRADE (Grading of Recommendations Assessment, Development and Evaluation) systematic review. BMJ Open (2017) 7:e016326. doi: 10.1136/bmjopen-2017-016326

52. Compalati E, Braido F, Canonica GW. An update on allergen immunotherapy and asthma. Curr Opin Pulm Med. (2014) 20:109-17. doi: 10.1097/MCP.0000000000000016

53. Calamita Z, Saconato H, Pelá AB, Atallah AN. Efficacy of sublingual immunotherapy in asthma: systematic review of randomized-clinical trials using the cochrane collaboration method. Allergy (2006) 61:1162-72. doi: 10.1111/j.1398-9995.2006.01205.x

54. Normansell R, Kew KM, Bridgman AL. Sublingual immunotherapy for asthma. Cochrane Database Syst Rev. (2015) 8:CD011293. doi: 10.1002/14651858.CD011293.pub2

55. Lin SY, Erekosima N, Kim JM, Ramanathan M, Suarez-Cuervo C, Chelladurai $\mathrm{Y}$, et al. Sublingual immunotherapy for the treatment of allergic rhinoconjunctivitis and asthma: a systematic review. JAMA (2013) 309:127888. doi: 10.1001/jama.2013.2049

56. Di Rienzo V, Marcucci F, Puccinelli P, Parmiani S, Frati F, Sensi L, et al. Long-lasting effect of sublingual immunotherapy in children with asthma due to house dust mite: a 10-year prospective study. Clin Exp Allergy (2003) 33:206-10. doi: 10.1046/j.1365-2222.2003.01587.x

57. Dominguez-Ortega J, Delgado J, Blanco C, Prieto L, Arroabarren E, Cimarra $\mathrm{M}$, et al. Specific allergen immunotherapy for the treatment of allergic asthma: a review of current evidence. J Investig Allergol Clin Immunol. (2017) 27(Suppl. 1):1-35. doi: 10.18176/jiaci.0149

58. Roberts G, Hurley C, Turcanu V, Lack G. Grass pollen immunotherapy as an effective therapy for childhood seasonal allergic asthma. J Allergy Clin Immunol. (2006) 117:263-8. doi: 10.1016/j.jaci.2005.09.054

59. Eng PA, Reinhold M, Gnehm HP. Long-term efficacy of preseasonal grass pollen immunotherapy in children. Allergy (2002) 57:306-12. doi: 10.1034/j.1398-9995.2002.103264.x

60. Hedlin G, Wille S, Browaldh L, Hildebrand H, Holmgren D, Lindfors A, et al. Immunotherapy in children with allergic asthma: effect on bronchial hyperreactivity and pharmacotherapy. J Allergy Clin Immunol. (1999) 103:609-14. doi: 10.1016/S0091-6749(99)70232-0

61. Zielen S, Kardos P, Madonini E. Steroid-sparing effects with allergenspecific immunotherapy in children with asthma: a randomized controlled trial. J Allergy Clin Immunol. (2010) 126:942-9. doi: 10.1016/j.jaci.2010. 06.002

62. Stelmach I, Sobocinska A, Majak P, Smejda K, Jerzynska J, Stelmach W. Comparison of the long-term efficacy of 3- and 5-year house dust mite allergen immunotherapy. Ann Allergy Asthma Immunol. (2012) 109:274-8. doi: 10.1016/j.anai.2012.07.015

63. Cools M, Van Bever HP, Weyler JJ, Stevens WJ. Long-term effects of specific immunotherapy, administered during childhood, in asthmatic patients allergic to either house-dust mite or to both house-dust mite and grass pollen. Allergy (2000) 55:69-73. doi: 10.1034/j.1398-9995.2000. 00191.x

64. Asamoah F, Kakourou A, Dhami S, Lau S, Agache I, Muraro A, et al. Allergen immunotherapy for allergic asthma: a systematic overview of systematic reviews. Clin Transl Allergy (2017) 7:25. doi: 10.1186/s13601-017-0160-0 
65. Kim JM, Lin SY, Suarez-Cuervo C, Chelladurai Y, Ramanathan M, Segal $\mathrm{JB}$, et al. Allergen-specific immunotherapy for pediatric asthma and rhinoconjunctivitis: a systematic review. Pediatrics (2013) 131:1155-67. doi: 10.1542/peds.2013-0343

66. Canonica GW, Cox L, Pawankar R, Baena-Cagnani CE, Blaiss M, Bonini $\mathrm{S}$, et al. Sublingual immunotherapy: world allergy organization position paper 2013 update. World Allergy Organ J. (2014) 7:6. doi: 10.1186/1939-455 $1-7-6$

67. Pajno GB, Barberio G, De Luca F, Morabito L, Parmiani S. Prevention of new sensitizations in asthmatic children monosensitized to house dust mite by specific immunotherapy. a six-year follow-up study. Clin Exp Allergy (2001) 31:1392-7. doi: 10.1046/j.1365-2222.2001.01161.x

68. Inal A, Altintas DU, Yilmaz M, Karakoc GB, Kendirli SG, Sertdemir Y. Prevention of new sensitizations by specific immunotherapy in children with rhinitis and/or asthma monosensitized to house dust mite. J Investig Allergol Clin Immunol. (2007) 17:85-91.

69. Di Bona D, Plaia A, Leto-Barone MS, La Piana S, Macchia L, Di Lorenzo G. Efficacy of allergen immunotherapy in reducing the likelihood of developing new allergen sensitizations: a systematic review. Allergy (2017) 72:691-704. doi: 10.1111/all.13104

70. Di Lorenzo G, Leto-Barone MS, La Piana S, Plaia A, Di Bona D. The effect of allergen immunotherapy in the onset of new sensitizations: a meta-analysis. Int Forum Allergy Rhinol. (2017) 7:660-69. doi: 10.1002/alr. 21946

71. Kristiansen M, Dhami S, Netuveli G, Halken S, Muraro A, Roberts G, et al. Allergen immunotherapy for the prevention of allergy: a systematic review and meta-analysis. Pediatr Allergy Immunol. (2017) 28:18-29. doi: $10.1111 /$ pai. 12661

72. Burgess JA, Walters EH, Byrnes GB, Matheson MC, Jenkins MA, Wharton CL, et al. Childhood allergic rhinitis predicts asthma incidence and persistence to middle age: a longitudinal study. $J$ Allergy Clin Immunol. (2007) 120:863-9. doi: 10.1016/j.jaci.2007.0 7.020

73. Möller C, Dreborg S, Ferdousi HA, Halken S, Høst A, Jacobsen L, et al. Pollen immunotherapy reduces the development of asthma in children with seasonal rhinoconjunctivitis (the PAT-study). J Allergy Clin Immunol. (2002) 109:251-6. doi: 10.1067/mai.2002.121317

74. Jacobsen L, Niggemann B, Dreborg S, Ferdousi HA, Halken S, Høst $A$, et al. Specific immunotherapy has long-term preventive effect of seasonal and perennial asthma: 10-year follow-up on the PAT study. Allergy (2007) 62:943-8. doi: 10.1111/j.1398-9995.2007.01 451.x

75. Niggemann B, Jacobsen L, Dreborg S, Ferdousi HA, Halken S, Høst A, et al. Five-year follow-up on the PAT study: specific immunotherapy and long-term prevention of asthma in children. Allergy (2006) 61:855-9. doi: 10.1111/j.1398-9995.2006.01068.x

76. Valovirta E, Berstad AK, de Blic J, Bufe A, Eng P, Halken S, et al. Design and recruitment for the GAP trial, investigating the preventive effect on asthma development of an SQ-standardized grass allergy immunotherapy tablet in children with grass pollen-induced allergic rhinoconjunctivitis. Clin Ther. (2011) 33:1537-46. doi: 10.1016/j.clinthera.2011.09.013

77. Valovirta E, Petersen TH, Piotrowska T, Laursen MK, Andersen JS, Sørensen $\mathrm{HF}$, et al. Results from the 5-year SQ grass sublingual immunotherapy tablet asthma prevention (GAP) trial in children with grass pollen allergy. J Allergy Clin Immunol. (2018) 141:529.e13-38. doi: 10.1016/j.jaci.2017. 06.014

78. Novembre E, Galli E, Landi F, Caffarelli C, Pifferi M, De Marco E, et al. Coseasonal sublingual immunotherapy reduces the development of asthma in children with allergic rhinoconjunctivitis. J Allergy Clin Immunol. (2004) 114:851-7. doi: 10.1016/j.jaci.2004.07.012

79. Marogna M, Tomassetti D, Bernasconi A, Colombo F, Massolo A, Businco $\mathrm{AD}$, et al. Preventive effects of sublingual immunotherapy in childhood: an open randomized controlled study. Ann Allergy Asthma Immunol. (2008) 101:206-11. doi: 10.1016/S1081-1206(10)60211-6

80. Zolkipli Z, Roberts G, Cornelius V, Clayton B, Pearson S, Michaelis L, et al. Randomized controlled trial of primary prevention of atopy using house dust mite allergen oral immunotherapy in early childhood. J Allergy Clin Immunol. (2015) 136:1541-1547.e11. doi: 10.1016/j.jaci.2015.04.045

81. Melioli G, Passalacqua G, Canonica GW, Baena-Cagnani CE, Matricardi P. Component-resolved diagnosis in pediatric allergic rhinoconjunctivitis and asthma. Curr Opin Allergy Clin Immunol. (2013) 13:446-51. doi: 10.1097/ACI.0b013e32836274d8

82. Fiocchi A, Pajno G, La Grutta S, Pezzuto F, Incorvaia C, Sensi L, et al Safety of sublingual-swallow immunotherapy in children aged 3 to 7 years. Ann Allergy Asthma Immunol. (2005) 95:254-8. doi: 10.1016/S1081-1206(10) 61222-7

83. Agostinis F, Tellarini L, Canonica GW, Falagiani P, Passalacqua G. Safety of sublingual immunotherapy with a monomeric allergoid in very young children. Allergy (2005) 60:133. doi: 10.1111/j.1398-9995.2004.00616.x

84. Shamji MH, Kappen JH, Akdis M, Jensen-Jarolim E, Knol EF, Kleine-Tebbe J, et al. Biomarkers for monitoring clinical efficacy of allergen immunotherapy for allergic rhinoconjunctivitis and allergic asthma: an EAACI position paper. Allergy (2017) 72:1156-73. doi: 10.1111/all.13138

85. Tosca MA, Pistorio A, Accogli A, Silvestri M, Rossi GA, Ciprandi G. Egg allergy: the relevance of molecular-based allergy diagnostics. Clin Exp Allergy (2014) 44:1094-5. doi: 10.1111/cea.12360

Conflict of Interest Statement: The authors declare that the research was conducted in the absence of any commercial or financial relationships that could be construed as a potential conflict of interest.

Copyright (C) 2018 Tosca, Licari, Olcese, Marseglia, Sacco and Ciprandi. This is an open-access article distributed under the terms of the Creative Commons Attribution License (CC BY). The use, distribution or reproduction in other forums is permitted, provided the original author(s) and the copyright owner(s) are credited and that the original publication in this journal is cited, in accordance with accepted academic practice. No use, distribution or reproduction is permitted which does not comply with these terms. 